\title{
LATE RESULTS OF SENNING OPERATION
}

Mikko Kirjavainen, MD

Juha-Matti Happonen, MD

Ilmo Louhimo, MD
Objectives: Few data exist for long-term results after the Senning operation for transposition of the great arteries. Sinus node dysfunction and systemic ventricular dysfunction have been the main problems. We evaluated risk factors for late death and the incidence of late death, sinus node dysfunction, and right ventricular dysfunction in 100 patients. Methods: The study was a retrospective analysis with a mean follow-up time of $12.8 \pm 3.1$ years. No patients were lost to follow-up. Patients were divided in 2 groups according to ventricular septal defect (73 simple, 27 complex). The electrocardiogram, ambulatory electrocardiogram, echocardiogram, and chest radiograph were reviewed for each patient. Results: The overall mortality rate was $10 \%$. The actuarial survival was $\mathbf{9 0 \%}$ (simple) and $\mathbf{7 8 \%}$ (complex); the probability of staying in sinus rhythm was $34 \%$ and $7 \%$, and the probability of normal right ventricular function was $52 \%$ and $39 \%$, respectively, 15 years after operation. The incidence of sinus node dysfunction increased gradually over time, although the incidence of right ventricular dysfunction increased rapidly after 10 years of follow-up. Late deaths, arrhythmias, and right ventricular dysfunction were significantly more frequent in the complex group. Right ventricular dysfunction and active arrhythmias were risk factors for late death. Conclusion: Long-term follow-up after the Senning operation shows increasing incidence of sinus node dysfunction and right ventricular dysfunction over time. Deteriorating right ventricular function is a major concern. Its early recognition and initiation of appropriate management to preserve cardiac function is an important follow-up goal. (J Thorac Cardiovasc Surg 1999;117:488-95)
$T^{\mathrm{T}}$ he Senning operation for transposition of the great arteries (TGA) was first introduced by Senning ${ }^{1}$ in 1958. However, during the 1960s and 1970s, atrial repair according to Mustard was a more dominant method. The Senning operation gained more ground after a revival made by Quaegebeur and associates ${ }^{2}$ in the late 1970s. The main change between the 2 techniques was that the Senning operation used very little, if any, foreign material for the surgical correction of TGA. After both types of atrial switch, late problems are seen, mainly in the form of atrial arrhythmias and

From Helsinki University Central Hospital, Hospital for Children and Adolescents, Helsinki, Finland.

Received for publication March 19, 1998; revisions requested June 1, 1998; revisions received Sept 8, 1998; accepted for publication Sept 10, 1998.

Address for reprints: Mikko Kirjavainen, MD, Helsinki University Central Hospital, Hospital for Children and Adolescents, PL 281, Helsinki 00029 HYKS, Finland.

Copyright (C) 1999 by Mosby, Inc.

$0022-5223 / 99 \$ 8.00+0 \quad \mathbf{1 2 / 1 / 9 4 4 9 5}$ right ventricular dysfunction (RVD). There are few long-term follow-up studies on patients who have undergone a Senning operation. ${ }^{3-6}$

Between 1978 and 1991, 133 patients with TGA, including other cardiac anomalies, underwent the Senning operation in one single hospital in Finland. After that era, the Senning operation has been performed in only a few cases. The early results were published in $1985 .^{7}$ We report the long-term results of the first 100 patients with either simple TGA or TGA and ventricular septal defect (VSD).

The purpose of our study was to determine the incidence of late death, sinus node dysfunction (SND), and RVD and to compare incidence of these late complications in patients who have TGA with or without VSD. We also evaluated risk factors for late death.

\section{Patients and methods}

The study was a retrospective follow-up study (mean follow-up time, $12.8 \pm 3.1$ years). Data were collected between January 1994 and April 1997 from medical records and from 
Table I. Diagnosis in 100 patients with TGA who underwent the Senning operation

\begin{tabular}{lc}
\hline Diagnosis & No. \\
\hline TGA & 56 \\
TGA + VSD & 17 \\
TGA + PDA & 13 \\
TGA + VSD + PDA & 9 \\
TGA + LVOTO & 4 \\
TGA + VSD + LVOTO & 1 \\
\hline
\end{tabular}

$P D A$, Patent ductus arteriosus; $L V O T O$, left ventricular outflow tract obstruction (dynamic).

the information obtained during the last control visits. At the last follow-up visits, patients underwent echocardiography, ambulatory electrocardiography, and chest radiography. Right ventricular function was subjectively assessed by an experienced pediatric cardiologist according to contraction pattern, wall thickness, ventricular dimensions, and septal movement during an echocardiographic examination. The presence and the degree of tricuspid regurgitation (TR) was also evaluated with Doppler echocardiography. Twelve-lead resting electrocardiography and 24-hour ambulatory electrocardiographic monitoring were used for evaluation for cardiac rhythm. The cardiac rhythm was classified as normal sinus rhythm, SND, and complete atrioventricular block (CAVB). Patients with SND were further classified as having mild, moderate, or severe SND, according to resting bradycardia level, chronotropic response to exercise, pauses during Holter monitoring, and active tachyarrhythmias. Mild SND was defined as the presence of atrial or junctional rhythm with good chronotropic response and without any important bradycardia. In moderate SND there was constant junctional rhythm or junctional rhythm with intermittent atrial rhythm with decreased chronotropic response and moderate bradycardia. Some patients had active tachyarrhythmias. Severe SND was defined as the presence of junctional rhythm or atrial escape rhythm with poor chronotropic response and marked bradycardia significant enough to require permanent pacemaker insertion.

Patient characteristics. Between October 1978 and August 1988, 100 patients with TGA or with TGA and VSD underwent the Senning operation in Helsinki University Children's Hospital. The patients were classified to the simple group if the interventricular septum was intact (simple, $\mathrm{n}$ $=73$ ) or to the complex group if there was a coexisting VSD (complex, $\mathrm{n}=27$; Table I). Patients with multiple associated cardiac anomalies, such as double-outlet right ventricle and coarctation of the aorta, were excluded. The operations were performed by 3 surgeons. Mean age at operation was 6.9 months, and there was a tendency over time to operate at an earlier age with the age at operation decreasing from 12 months to 4 months.

All patients, except one, underwent preoperative balloon atrial septostomy. Twelve percent of the patients in the simple group and $39 \%$ of the patients in the complex group had neu-
Table II. Perioperative data with mean values and range for the patients with simple or complex TGA

\begin{tabular}{lll}
\hline & \multicolumn{1}{c}{$\begin{array}{c}\text { Simple } \\
(n=73)\end{array}$} & $\begin{array}{l}\text { Complex } \\
(n=27)\end{array}$ \\
\hline $\begin{array}{l}\text { Age at operation (mo) } \\
\text { Aortic crossclamp time } \\
\quad(m i n)\end{array}$ & $\begin{array}{l}7.0(0.3-20) \\
48(31-75)\end{array}$ & $\begin{array}{l}6.8(1.5-16) \\
63(34-85)\end{array}$ \\
$\begin{array}{ll}\text { Bypass time (min) } \\
\text { Total arrest time (min) }\end{array}$ & $94(65-148)$ & $129(81-236)$ \\
Mean ICU time (days) & $8.5(0.5-34), 69 \% *$ & $8.6(1.3-26), 75 \% *$ \\
Early deaths (No.) & 0 & $11(3-32)$ \\
\hline
\end{tabular}

$I C U$, Intensive care unit.

*The frequency of total arrest used.

Table III. Risk factor analysis (univariate) for death after Senning operation

\begin{tabular}{lcc}
\hline Risk factor & $H R$ & $95 \%$ CI \\
\hline Year of birth & 1.15 & $0.87-1.54$ \\
Year of operation & 1.22 & $0.89-1.65$ \\
Age at operation & 0.95 & $0.79-1.13$ \\
VSD & 2.62 & $0.76-9.10$ \\
SND & 1.61 & $0.34-7.59$ \\
RVD & 2.49 & $0.72-8.65$ \\
Active arrhythmias & 6.63 & $1.70-25.87$ \\
\hline
\end{tabular}

$H R$, Hazard ratio.

rologic problems, such as delay in psychomotor development and absence episodes clinically resembling partial epilepsy. Three patients had preoperative cerebral infarction resulting in hemiplegia.

Surgical technique. The surgical technique was as described by Senning. ${ }^{1}$ The suture line in the vicinity of the sinus node was placed close to the superior vena caval orifice in an attempt to avoid direct damage to the sinus node. All operations were performed with the patient in deep hypothermia $\left(18^{\circ} \mathrm{C}-25^{\circ} \mathrm{C}\right)$. The perioperative variables are summarized in Table II. The bypass time, aortic crossclamp time, and time of total circulatory arrest shortened considerably over time.

Follow-up. No patients were lost to follow-up. Average follow-up time was 12.8 years (range, 6.2-18.4 years). Only 13 patients were followed up for less than 10 years. Patients were seen at follow-up visits by experienced cardiologists at least every 2 years.

Statistics. Survival analysis for late death, rhythm disturbances, and RVD were performed by the Kaplan-Meier method. The log-rank test was used to estimate the difference between the 2 groups. Cox proportional hazard regressions were used to assess risk factors for late death. Variables likely to affect survival were entered in a univariate analysis (Table III). To identify independent predictors of late death, a multifactorial stepwise Cox proportional hazard regression analysis with SND and RVD entered as time-dependent co- 


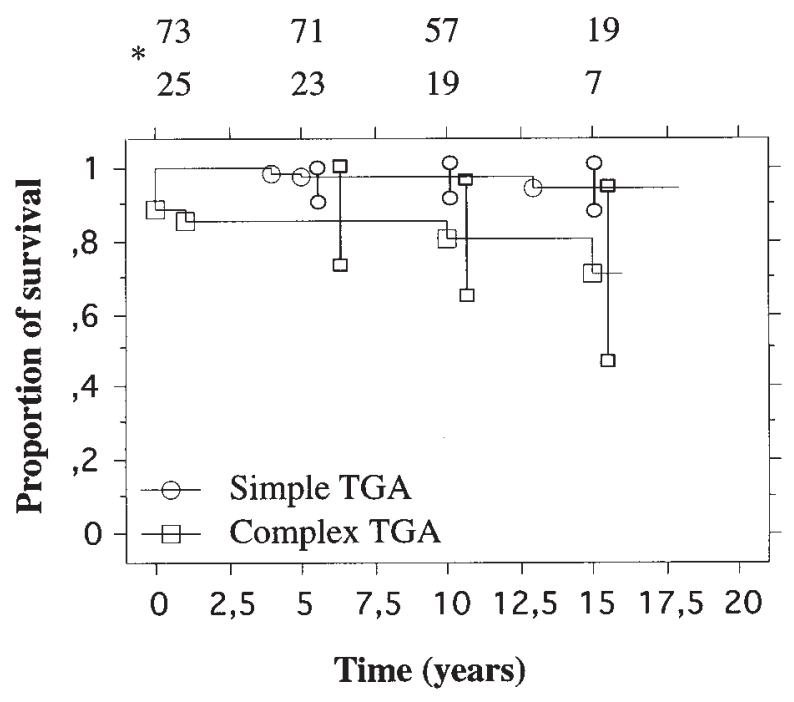

Fig 1. Probability of surviving after the Senning operation. *No. of patients at risk. Vertical lines represent 95\% CI at 5-, 10-, and 15-year follow-up. (Kaplan-Meier cumulative survival plot; $P=.01$, log-rank test.)

variables was performed. Statistical software used were StatView (Version 4.51; Abacus Concepts, Berkeley, Calif) and S-Plus (Version 4.5; MathSoft, Inc, Seattle, Wash).

\section{Results}

Perioperative period and early deaths. There were no early deaths in the simple group. In the complex group, 2 patients $(8.3 \%)$ died within 12 hours of operations as the result of severe heart failure. Mean intensive care unit time was 8 days in the simple group and 11 days in the complex group. After the operation, 3 patients (3\%) had CAVB.

Reoperation. Four reoperations were performed on 3 patients. Pneumonectomy was required in 1 patient in the simple group because of total occlusion of the pulmonary veins and recurrent pneumonia 6 years after the Senning operation. In the simple group, there was 1 reoperation in 73 patients, and in the complex group there were 3 reoperations in 25 patients. One patient had severe TR 5 years after the Senning operation. She underwent valvuloplasty with a later tricuspid valve replacement. Another patient in the complex group had severe heart failure 9 years after the operation and underwent heart transplantation.

Late deaths. There were 8 late deaths, 4 in the simple group and 4 in the complex group. In the simple group, 4 patients died 7.5 years (mean) after the Senning operation (range, 3-13 years). One of these patients died of a noncardiac cause. Two patients died suddenly. They both had mild to moderate RVD. One of them had atrial flutter, and the other was in stable sinus rhythm. The fourth patient in the simple group died of cerebral abscess. He had no RVD, but mild SND.

In the complex group, 4 patients died 6.6 years (mean) after the Senning operation (range, 3 months-15 years). There were 2 sudden deaths. The third patient died of pulmonary hypertension and right ventricular failure 3 months after the Senning operation. The fourth patient had severe TR and progressively worsening RVD 1 year after the operation. He also had severe SND and a pacemaker. No autopsy was done.

In multivariate analysis of the risk of late death with RVD and SND included as time-dependent covariables RVD (hazard ratio, 11.4; 95\% confidence intervals [CI], 2.8 and 46.9) and arrhythmias (hazard ratio, 5.1; 95\% CI, 1.1 and 22.8) emerged as independent risk factors.

The overall survival for the patients having the Senning operation was $90 \%$. In the simple group the survival was $97 \%$, and in the complex group the survival was $78 \%$. On the other hand, the probability of survival after 16 years of follow-up was 90\% (95\% CI, 0.89 and 1.00) in the simple group and 70\% (95\% CI, 0.48 and 0.93 ) in the complex group. The difference between groups was statistically significant $(P=.01$; Fig 1).

Rhythm disturbances. Cardiac rhythm at final follow-up is summarized in Fig 2. Sinus rhythm was retained in $37 \%$ of the patients in the simple group and in $19 \%$ of the patients in the complex group during follow-up. A rapid decline in the percentage of sinus rhythm occurred during the first 4 years after the Senning operation. After this period, a continuing but more gradual decrease occurred (Fig 3). The probability of maintaining sinus rhythm was $60 \%$ (95\% CI, 0.47 and 0.70 ), $55 \%$ (95\% CI, 0.33 and 0.57 ), and $34 \%$ (95\% CI, 0.21 and 0.46 ) in the simple group, and $38 \%$ (95\% CI, 0.18 and 0.56), 32\% (95\% CI, 0.11 and 0.46), and $7 \%$ (95\% CI, 0.00 and 0.20$)$ in the complex group at 5, 10, and 15 years after the Senning operation, respectively. The difference between the 2 groups was statistically significant $(P=.04)$. In the simple group, most patients with SND had only mild disease, whereas in the complex group most patients had moderate or severe SND (Fig 2).

The overall incidence of tachyarrhythmias was $8 \%$. Three patients had intra-atrial re-entrant tachycardias, and 5 patients had other supraventricular tachyarrhythmias. Four patients had CAVB, 3 directly after the operation and 1 during follow-up 5 years after the operation.

Fifteen patients $(21 \%)$ in the simple group and 9 patients $(36 \%)$ in the complex group required pacemak- 


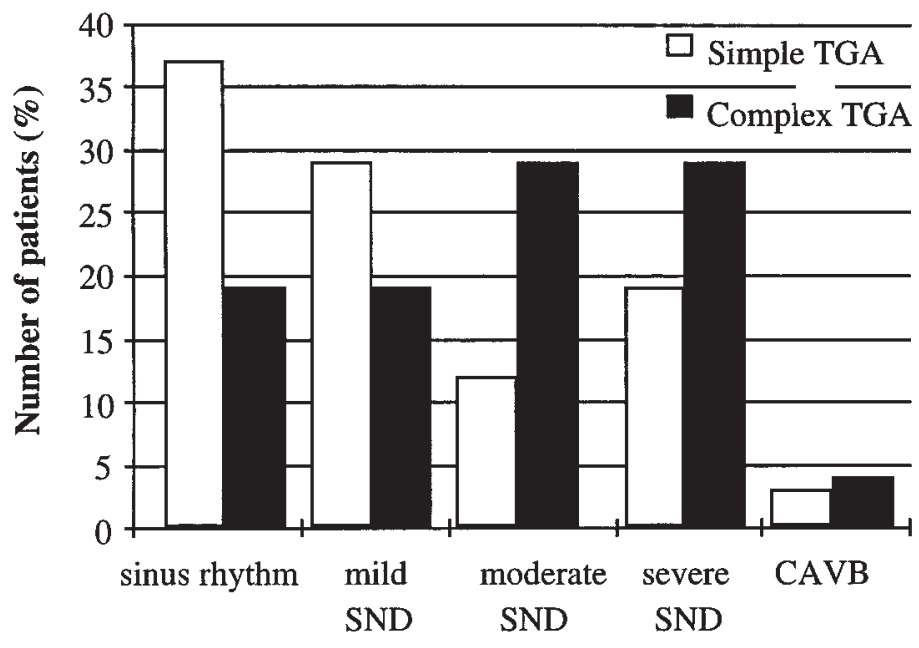

Type of cardiac rhythm

Fig 2. Cardiac rhythm at last follow-up, with a mean follow-up time of 12.8 years.

er implantation. The indications for pacemaker implantations were SND with severe bradycardia in $68 \%$, CAVB in $16 \%$, and SND with arrhythmia and antiarrhythmic treatment in $16 \%$. The mean time of implantations was 8.3 years after the Senning operation.

Right ventricular function and TR. RVD was a late problem in our study. RVD was diagnosed at a mean interval of 10.3 years after the Senning operation. At the end of the follow-up, $82 \%$ of the patients in the simple group and $62 \%$ of the patients in the complex group had normal systemic ventricular function. The incidence of moderate or severe RVD was higher in the complex group (Fig 4). All patients with significant RVD were treated with an angiotensin-converting enzyme inhibitor (enalapril) alone or combined with digoxin. Still, 75\% of patients with RVD had no symptoms.

The probability of maintaining normal right ventricular function declined rapidly after 10 years of followup. The probability of normal right ventricular function was considerably lower in the complex group $(P=.03)$. Fig 5 depicts actuarial freedom from RVD in operative survivors. The probability of normal right ventricular function was $97 \%$ (95\% CI, 0.93 and 1.00), 89\% (95\% CI, 0.81 and 0.97 ), and $52 \%$ (95\% CI, 0.34 and 0.70 ) in the simple group, and $92 \%$ (95\% CI, 0.75 and 1.00), 75\% (95\% CI, 0.58 and 0.93 ), and 39\% (95\% CI, 0.15 and 0.64 ) in the complex group at 5, 10, and 15 years after the Senning operation, respectively.

All patients with RVD also had TR. In $64 \%$ of patients, TR preceded the onset of RVD by a mean interval of 3.6 years.

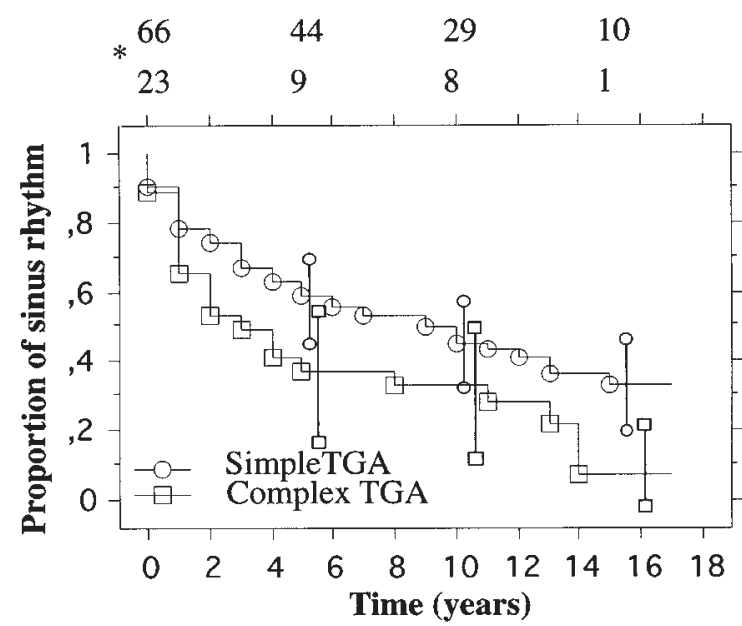

Fig 3. Probability of maintaining sinus rhythm after the Senning operation. *No. of patients at risk. Vertical lines represent 95\% CI at 5-, 10-, and 15-year follow-up. (KaplanMeier cumulative survival plot; $P=.04$, log-rank test.)

Significant TR was found in 5 patients $(7 \%)$ in the simple group and in $4(16 \%)$ patients in the complex group. One patient with severe TR underwent valvuloplasty with a later tricuspid valve replacement. Another patient with moderate TR and severe RVD underwent successful heart transplantation. Two other patients died suddenly with RVD. TR was detected with echocardiography at an average of 7.5 years after the Senning operation. Forty-six percent of patients in the simple group and $52 \%$ of patients in the complex group 


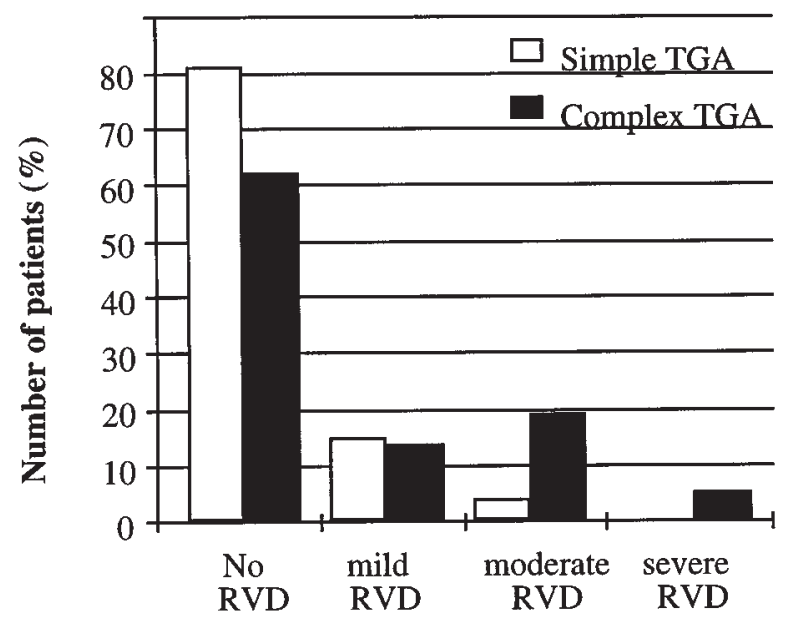

Degree of right ventricular function

Fig 4. Right ventricular function at last follow-up, with a mean follow-up time of 12.8 years: echocardiographic assessment.

had mild or physiologic TR. All patients who had clinically important TR were treated with enalapril.

Other late cardiac problems. Two patients in both groups (simple [3\%] and complex [8\%]) had dynamic left ventricular outflow tract obstruction. Mild mitral valve regurgitation was found in 1 patient in both groups. They both also had TR. Six years after the operation, 1 patient had complete left pulmonary vein obstruction and recurrent pneumonia. He underwent pneumonectomy. Another patient in the simple group had slight narrowing of the venous pathway with increased flow velocity at Doppler echocardiography, but with clinically normal venous pressure.

Functional status. At final follow-up, $86 \%$ of the patients in the simple and $83 \%$ of the patients in the complex group were in New York Heart Association (NYHA) class I. The remainder of the patients in the simple group were in class II. One patient in the complex group was in class III (5\%).

Neurologic problems. Neurologic problems were found in 13 patients, 10 patients in the simple group $(14 \%)$ and 3 patients in the complex group (14\%). Four patients had absence episodes clinically resembling partial epilepsy; 5 patients had delay in psychomotor development; 3 patients had learning disabilities; and 1 patient had a mild hemiplegia. Problems cumulated in patients who underwent the operation earlier during this series. Eleven of 13 patients with neurologic problems underwent the operation before 1982. The mean age at the time of the Senning operation was over 12 months in these patients. Five patients had the same

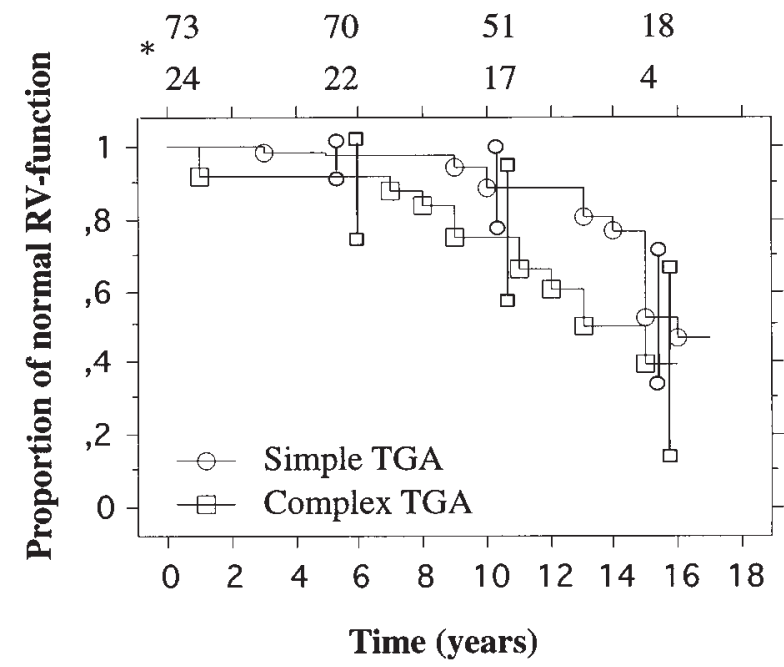

Fig 5. Probability of normal right ventricular function after the Senning operation. *Number of patients at risk. Vertical lines represent 95\% CI at 5-, 10-, and 15-year follow-up. (KaplanMeier cumulative survival plot; $P=.03, \log$-rank test.)

symptoms before the operation. Three of the patients had preoperative cerebral infarction.

\section{Discussion}

The Senning operation, which was performed in our institution from the late 1970s to the early 1990s, uses little, if any, foreign material to reroute systemic and pulmonary venous return, thereby optimizing the potential for atrial growth and contraction and minimizing the possibility for pulmonary venous and caval obstructions. ${ }^{8,9}$ In this respect, the results at our institution improved compared with an unpublished Mustard series. However, rhythm disturbances and RVD have remained the main problems during late follow-up, as in many other studies. ${ }^{3,10,11}$ Patients who have had the Senning operation have a tendency to experience the development of SND, with bradycardia and atrial arrhythmias. On the other hand, right ventricular function deteriorates and the ventricle dilates. This may lead to the onset of TR, which again causes excess volume load to the ventricle, causing further dilation. The ensuing increase in atrial volume and pressure further contribute to the development of atrial arrhythmias.

It is obvious that SND is not inherent to the basic disease but secondary to the surgical interventions. ${ }^{12,13}$ Postulated mechanisms for SND include disruption of sinus node arterial flow and direct iatrogenic damage to the sinus node and atrial muscle. Extensive suture lines in the atria favor the re-entry mechanism. ${ }^{10,12,13}$ The incidence of moderate or severe SND was higher in the complex group. The proportion of patients in sinus 
rhythm decreased progressively. The probability of sinus rhythm after 17 years of follow-up was $31 \%$ with patients in the simple group and $7 \%$ with patients in the complex group. SND became more frequent with time, but it could not be established as a risk factor for late death. These findings have also been established by others. ${ }^{10,14}$ Most patients with SND did not experience important limitations in daily activities.

The loss of sinus rhythm and the appearance of tachyarrhythmias in patients with atrial switch repair are well documented in many Mustard studies. ${ }^{11,15,16}$ The incidence of symptomatic tachyarrhythmias has varied between $5 \%$ and $15 \%$. Atrial flutter has been found ominous, especially with RVD, and its appearance increases the risk of sudden death 4-fold after the Mustard operation. In addition, the appearance of atrial flutter seems to be an early sign of decreasing right ventricular function. ${ }^{11}$ Our results support these earlier findings, showing a hazard ratio of 5.1 for late death in patients with active arrhythmias. The incidence of sudden death in patients with atrial switch repair has varied between $2 \%$ and $9 \% .{ }^{16}$ In our study, the incidence of sudden cardiac death was $4 \%$.

There were 24 pacemaker implantations (24\%) in our study. The number is high compared with other longterm follow-up studies. ${ }^{3,4,6,10} \mathrm{We}$ implanted a pacemaker if the patient had significant bradycardia or long pauses (over 3 seconds) or if the patient already had documented atrial flutter necessitating treatment with antiarrhythmic drugs. Pacing the heart at normal physiologic rates with AAI or DDD modes is hoped to retard ventricular dilation and thus maintain better systemic ventricular function. Also, keeping the atrial pacing rates high enough helps to avoid atrial flutter associated with bradycardia. Pacing does not seem to prevent sudden cardiac death after atrial switch, which most often seems to be secondary to an atrial tachyarrhythmia with $1: 1$ conduction. ${ }^{17}$

Postoperative systemic ventricular function is a major concern after atrial repair of TGA. It is not as common as rhythm disturbances, but it has a great clinical importance. In our study, RVD was an independent risk factor for late death with a hazard ratio of 11.4. We estimated right ventricular function using echocardiography. Despite its limitations, it may be the best method available for clinical work at the moment. ${ }^{18-20}$ Several factors contribute to RVD: SND with bradycardia, TR, preoperative hypoxia, and perioperative factors. ${ }^{20,21} \mathrm{In}$ addition, the ability of the right ventricle to perform efficiently in the systemic position has been questioned for anatomic reasons. ${ }^{21,22}$

In many studies RVD was detected at the end of the follow-up. $\mathrm{Mee}^{23}$ estimated the incidence of RVD at
$10 \%$ or more after the first 10 years. In our study, the incidence of RVD was $8 \%$ for patients with simple TGA and $26 \%$ for patients with complex TGA. Twenty-five percent of the patients had symptoms. Unfortunately, the incidence of RVD increased progressively after 10 years. The probability of maintaining normal systemic ventricular function 16 years after the Senning operation was only $52 \%$ in the simple group and 39\% in the complex group. With angiographic studies, one could probably detect an even greater amount of patients with impaired right ventricular function. In the study by Rubay and associates, ${ }^{24}$ only $44 \%$ of patients had an ejection fraction higher than 0.50 and an end-diastolic volume not exceeding $80 \mathrm{~mL} \times \mathrm{m}^{-2}$ after 4 years (mean) of follow-up. In addition, in the study by Bender and associates, ${ }^{9}$ already $60 \%$ of patients had an abnormal response to exercise after 3 years of follow-up. On the other hand $97.5 \%$ of them were in NYHA class I.

Maintaining adequate systemic ventricular function is paramount for long-term survival after atrial switch operations for TGA. Afterload-reducing medical therapy with angiotensin-converting enzyme inhibitors has been shown to be beneficial in long-term follow-up of patients with left ventricular dysfunction. ${ }^{25-27}$ This seems to be true even if the patients are free of symptoms. It is probable that the aggressive use of afterload reduction could also delay the deterioration of systemic ventricular function in patients who have undergone a Senning operation, although there are no published reports on the subject. Our group has used enalapril, an angiotensin-converting enzyme inhibitor, either alone or together with digoxin, in all patients showing significant RVD or moderate to severe TR.

At the moment there are not many surgical methods to deal with RVD. Tricuspid valve valvuloplasty or replacement can be considered if there is significant TR and the right ventricular function is reasonably good. Late staged conversion to arterial switch has been proposed in the face of RVD. However, the mortality rate of this procedure has been high..$^{21}$ Our group has elected not to pursue late arterial switch as a management option. Heart transplantation is the remaining possibility with end-stage heart failure. So far, 1 patient in our series has undergone heart transplantation.

Operative deaths for the Senning operation have been low (1\% to $9 \%)^{3,22,28-30}$ In our study there were no primary deaths in the simple group. Two patients in the complex group died within 12 hours after operation. Midterm survival has also been excellent with $90 \%$ to $95 \%$ of children surviving 10 years. ${ }^{9}$ In our study the overall mortality rate, including perioperative deaths, for 12.8 years (mean) of follow-up was $10 \%$. There 
was 1 noncardiac death. The probability of surviving 16 years was $94 \%$ in the simple group and $70 \%$ in the complex group. One half of the late deaths were sudden. RVD and active arrhythmias constituted risk factors for late death. However, SND alone did not emerge as a risk factor.

VSD with TGA forms a group of its own. Both the morbidity and mortality rates of the Senning procedure for complex TGA have been high. George and associates $^{30}$ reported a 3 -fold late mortality rate, compared with the patients with simple TGA, a result similar to our series. In short-term results, the main difference in our study was that there were 2 early deaths (7.4\%) in the complex group versus no early death in the simple group. The incidence of postoperative CAVB was 5.2fold in the patients with complex TGA; they also received twice as many pacemakers. During follow-up, patients with complex TGA had twice as much RVD, with moderate and severe RVD cumulating in the complex group. The higher incidence of these late problems, especially RVD, in the complex group may be due to iatrogenic damage to the tricuspid valve as a result of VSD closure. Organic damage to the tricuspid valve may also result from the presence of the VSD itself. ${ }^{23}$

Despite SND and RVD, most of our patients had a good functional status. Most of the patients were in New York Heart Association class I or II. The presence of SND had little influence on the patients' functional classification, unless they also had active atrial arrhythmias or bradycardia necessitating pacemaker implantation. On the other hand, our findings show that RVD after the Senning operation is a late phenomenon necessitating close follow-up through adulthood. It seems probable that, with time, increasing numbers of patients with atrial switch procedures will need heart transplantations.

We thank Hanna Oksanen, $\mathrm{PhD}$, for her expert help in statistical analysis of our data.

\section{REFERENCES}

1. Senning A. Surgical correction of transposition of the great vessels. Surgery 1959;45:966-80.

2. Quaegebeur JM, Rohmer J, Brom AG, Tinkelenberg J. Revival of the Senning operation in the treatment of transposition of the great arteries. Thorax 1977;32:517-24.

3. Helbing WA, Hansen B, Ottenkamp J, et al. Long-term results of atrial correction for transposition of the great arteries. J Thorac Cardiovasc Surg 1994;108:363-72.

4. Gilljam T, Eriksson BO, Solymar L, Jonsson M. Status of survivors after atrial redirection for transposition of the great arteries: a complete long-term follow-up. Acta Paediatr 1996;85:832-7.

5. Tronc F, Robin J, Ninet J, et al. Long term evaluation after atrial correction of transposition of the great arteries. In: Proceedings of the European Association for Cardio-thoracic Surgery, Ninth Congress, Paris: 1995. p. 308.

6. Reddy V, Sharma S, Cobanoglu A. Atrial switch (Senning procedure) in the era of arterial switch operation: current indication and results. Eur J Cardiothorac Surg 1996;10:546-50.

7. Louhimo I. Complete transposition in Finland. Int $\mathrm{J}$ Cardiol 1985;9:261-5.

8. Chin AJ, Sanders SP, Williams RG, et al. Two dimensional echocardiographic assessment of caval and pulmonary venous pathways after the Senning operation. Am J Cardiol 1983;52:118-26.

9. Bender HW, Stewart JR, Merrill WH, et al. Ten years' experience with the Senning operation for transposition of the great arteries. Ann Thorac Surg 1989;47:218-23.

10. Deanfield J, Camm J, Macartney F, et al. Arrhythmia and late mortality after Mustard and Senning operation for transposition of the great arteries. J Thorac Cardiovasc Surg 1988;96:569-76.

11. Gewillig M, Cullen S, Mertens B, et al. Risk factors for arrhythmia and death after Mustard operation for simple transposition of the great arteries. Circulation 1991;84:187-92.

12. Byrum JC, Bove EL, Sondheimer HM, et al. Hemodynamic and electrophysiologic results of the Senning procedure for transposition of the great arteries. Am J Cardiol 1986;58:138-42.

13. Menahem S, Ranjit MS, Stewart C, et al. Cardiac conduction abnormalities and rhythm changes after neonatal anatomical correction of transposition of the great arteries. Br Heart J 1992;67:246-9.

14. Haemmerli M, Bolens M, Friedli B. Electrophysiological studies after the Mustard and Senning operation for complete transposition. Do they have prognostic value? Int J Cardiol 1990;27:167-73.

15. Gelatt M, Hamilton RM, McCrindle B, et al. Arrhythmia and mortality after the Mustard procedure: a 30-year single-center experience. J Am Coll Cardiol 1997;29:194-201.

16. Paul MH, Wernovsky G. Transposition of the great arteries. In: Emmanouilides GC, Allen AD, Riemenschneider TA, Gutgesell HP, editors. Heart disease in infants, children, and adolescents including the fetus and young adult. 5th ed. Baltimore: Moss and Adams; 1995. p. 1154-224.

17. Garson A Jr. Chronic postoperative arrhythmia. In: Gillette PC, Garson A Jr, editors. Pediatric arrhythmias. Electrophysiology and pacing. Philadelphia: WB Saunders; 1990. p. 667-78.

18. Printz BF, Gersony WM, Apfel HD. Quantitation of right ventricular function in children. In: Proceedings of pediatric cardiology and cardiac surgery. Second World Congress, Hawaii: 1997. p. 71.

19. Nascimento R, Damiao LC, Bastos P, et al. Echo-Doppler study of right ventricular filling in asymptomatic patients with Senning operation for transposition of the great arteries. Am J Cardiol 1991;68:693-5.

20. Trowitzsch E, Colan SD, Sanders S. Global and regional right ventricular function in normal infants with transposition of the great arteries after Senning operation. Circulation 1985;72:1008-14.

21. Cochrane AD, Karl TR, Mee RBB. Staged conversion to arterial switch for late failure of the systemic right ventricle. Ann Thorac Surg 1993;56:854-62.

22. Graham TP Jr. Ventricular performance in congenital heart disease. Circulation 1991;84:2259-73.

23. Mee RBB. Severe right ventricular failure after Mustard or Senning operation. J Thorac Cardiovasc Surg 1986;92:385-90.

24. Rubay JE, de Halleux C, Jaumin P, et al. Long-term follow-up of the Senning operation for transposition of the great arteries in 
children under 3 months of age. J Thorac Cardiovasc Surg 1987;94:75-81.

25. Anonymous. Effect of enalapril on survival in patients with reduced left ventricular ejection fractions and congestive heart failure: the SOLVD investigators. N Engl J Med 1991;325:293302.

26. Anonymous. Effect of enalapril on mortality and the development of heart failure in asymptomatic patients with reduced left ventricular ejection fractions: the SOLVD investigators. N Engl J Med 1992;327:685-91.

27. Konstam MA, Rousseau MF, Kronenberg MW, et al. Effects of the angiotensin converting enzyme inhibitor enalapril on the long-term progression of left ventricular dysfunction in patients with heart failure. Circulation 1992;86:431-8.

28. Castaneda AR, Trusler GA, Paul MH, et al. The early results of treatment of simple transposition in the current era. J Thorac Cardiovasc Surg 1988;95:14-28.

29. Trusler GA, Castaneda AR, Rosenthal A, et al. Current results of management in transposition of the great arteries, with special emphasis on patients with associated ventricular septal defect. J Am Coll Cardiol 1987;10:1061-71.

30. George BL, Laks H, Klitzner TS, et al. Results of the Senning procedure in infants with simple and complex transposition of the great arteries. Am J Cardiol 1987;59:426-30.

\section{Bound volumes available to subscribers}

Bound volumes of The Journal of Thoracic and Cardiovascular Surgery are available to subscribers (only) for the 1999 issues from the Publisher, at a cost of $\$ 134.00$ for domestic, $\$ 165.85$ for Canadian, and $\$ 155.00$ for international subscribers for Vol 117 (January-June) and Vol 118 (July-December). Shipping charges are included. Each bound volume contains a subject and author index and all advertising is removed. Copies are shipped within 60 days after publication of the last issue of the volume. The binding is durable buckram with the Journal name, volume number, and year stamped in gold on the spine. Payment must accompany all orders. Contact Mosby, Inc, Subscription Services, 11830 Westline Industrial Drive, St Louis, MO 63146-3318, USA; phone 800-453-4351 or 314-453-4351.

Subscriptions must be in force to qualify. Bound volumes are not available in place of a regular Journal subscription. 